\title{
Improved pulmonary function in the nitrofen model of congenital diaphragmatic hernia following prenatal maternal dexamethasone and/or sildenafil
}

\author{
Carmen Mesas Burgos ', ${ }^{1,2}$, Erik G. Pearson' ${ }^{1}$, Marcus Davey', John Riley ${ }^{1}$, Huimin Jia' ${ }^{1}$ Pablo Laje' ${ }^{1}$, Alan W. Flake' and \\ William H. Peranteau'
}

\begin{abstract}
BACKGROUND: Pulmonary hypoplasia and hypertension is a leading cause of morbidity and mortality in congenital diaphragmatic hernia $(C D H)$. The etiologic insult occurs early in gestation highlighting the potential of prenatal interventions. We evaluated prenatal pharmacologic therapies in the nitrofen $\mathrm{CDH}$ model.
\end{abstract}

METHODS: Olive oil or nitrofen were administered alone or with dexamethasone (DM), sildenafil, or DM+sildenafil to pregnant rats. Newborn pups were assessed for lung function, structure and pulmonary artery (PA) flow and resistance.

RESULTS: Prenatal DM treatment of $\mathrm{CDH}$ pups increased alveolar volume density $(\mathrm{Vva})$, decreased interalveloar septal thickness, increased tidal volumes and improved ventilation without improving oxygenation or PA resistance. Sildenafil decreased PA resistance and improved oxygenation without improving ventilation or resulting in significant histologic changes. DM+sildenafil decreased PA resistance, improved oxygenation and ventilation while increasing $V v a$ and decreasing interalveolar septal and pulmonary arteriole medial wall thickness. Lung and body weights were decreased in pups treated with DM and/or sildenafil.

CONCLUSION: Prenatal DM or sildenafil treatment increased pulmonary compliance and decreased pulmonary vascular resistance respectively, and was associated with improved neonatal gas exchange but had a detrimental effect on lung and fetal growth. This study highlights the potential of individual and combined prenatal pharmacologic therapies for $\mathrm{CDH}$ management.

C ongenital diaphragmatic hernia $(\mathrm{CDH})$ results in abdominal viscera herniation into the chest during fetal ontogeny and impaired lung development. It presents with a spectrum of severity and, despite advances in care, survival rates remain low at $68-92 \%(1)$. Pulmonary hypertension $(\mathrm{PH})$ and hypoplasia are major contributors to the mortality and morbidity in $\mathrm{CDH}$ $(2,3)$. Due to abnormal pulmonary development, infants with $\mathrm{CDH}$ are born with varying degrees of pulmonary hypoplasia, delayed lung maturation, and abnormal pulmonary vasculature including arterial hypermuscularization and decreased arterial cross-sectional area $(4,5)$. In addition to structural anomalies, pulmonary vascular hyper reactivity contributes to persistent $\mathrm{PH}$ (6).

Advances in obstetrical care have resulted in the antenatal diagnosis of $\mathrm{CDH}$ and disease severity prediction in most affected fetuses (7-9). This progress and the fetal origin of the initial insult highlight the potential of fetal interventions to improve outcomes. Minimally invasive prenatal tracheal occlusion (TO) to stimulate lung growth is a surgical approach with early encouraging results (10). Surgical interventions, however, are not without limitations. Prenatal pharmacologic treatment of $\mathrm{PH}$ and hypoplasia is an alternative, and potentially less risky, therapeutic approach. Improvement in lung maturation and postnatal pulmonary function in $\mathrm{CDH}$ patients following maternal administration of prenatal steroids has been debated $(11,12)$. Animal models support accelerated lung maturation, improved lung morphology, and alterations in pulmonary biochemical pathways including increased surfactant and endothelial nitric oxide synthase production and decreased production of angiotensin converting enzyme following prenatal glucocorticoid administration (13-15). Sildenafil is a cyclic GMP-specific phosphodiesterase type 5 inhibitor used in postnatal treatment of $\mathrm{CDH}$ associated $\mathrm{PH}$ (16). In rat models, prenatal or neonatal treatment with sildenafil improved lung structure, increased vessel density and decreased right ventricular hypertrophy while increasing pulmonary expression of endothelial nitric oxide synthase, hypoxia-inducible factor- $1 / 2 \alpha$ and vascular endothelial growth factor $(17,18)$. However, morphologic and/or biochemical improvements do not necessarily correlate with improved pulmonary function and clinical outcomes. In this study, we evaluate the effect of pharmacologic agents previously shown to have beneficial morphologic and biochemical effects on postnatal respiratory function and pulmonary blood flow. Specifically, we hypothesize that prenatal administration of sildenafil and/or dexamethasone (DM) results in improved neonatal lung function

'The Center for Fetal Research, The Children's Hospital of Philadelphia, Philadelphia, Pennsylvania; ${ }^{2}$ Department for Women's and Children's Health, Division of Pediatric Surgery, Karolinska Institute, Stockholm, Sweden. Correspondence: William H. Peranteau (peranteauw@email.chop.edu)

Received 8 March 2016; accepted 12 April 2016; advance online publication 20 July 2016. doi:10.1038/pr.2016.127 
and pulmonary artery (PA) pressures and blood flow in the nitrofen-induced $\mathrm{CDH}$ rat model.

\section{RESULTS}

\section{Lung Weight, Body Weight, and Lw:Bw Ratio}

We ascertained whether prenatal DM and/or sildenafil had an effect on fetal lung and body growth (Figure 1). The lung weight (Lw): body weight $(\mathrm{Bw})$ ratio was significantly decreased in newborn $\mathrm{CDH}$ pups compared with controls and nitrofen exposed non-CDH fetuses. Prenatal administration of
$\mathrm{DM}$ and/or sildenafil decreased the $\mathrm{Bw}, \mathrm{Lw}$, and Lw:Bw ratio in $\mathrm{CDH}$ pups compared with both controls and nontreated $\mathrm{CDH}$ pups. A similar trend in reduction of $\mathrm{Lw}, \mathrm{Bw}$, and $\mathrm{Lw}$ : Bw ratio was seen in treated non-CDH pups compared with untreated non-CDH pups suggesting that the prenatal treatment had a negative effect on lung and fetal growth.

\section{Ventilation}

The effect of prenatal DM and/or sildenafil on pulmonary tidal volumes $(\mathrm{Vt})$ and neonatal gas exchange in newborn a

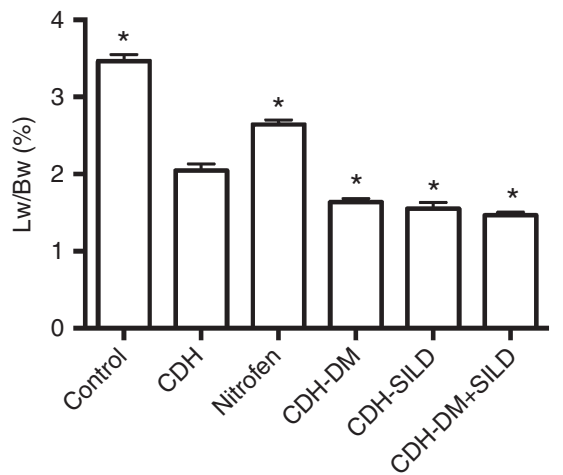

b

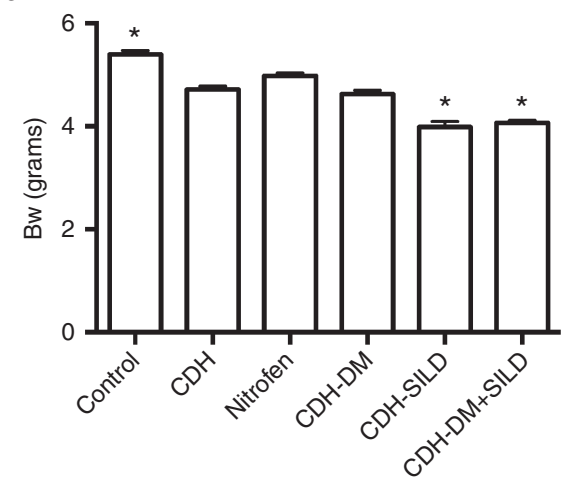

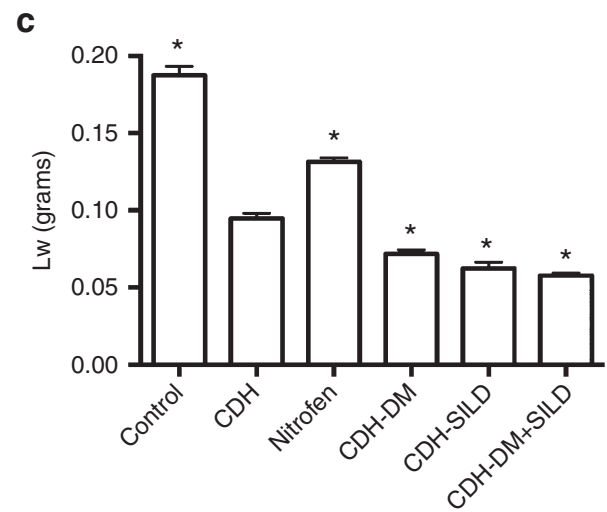

Figure 1. Lung weight:Body weight ratio. Dry lung and body weights of E21.5 fetuses were recorded. The Lw:Bw ratio (a), Bw (b) and Lw (c) of control $(n=$ 28), nontreated $\mathrm{CDH}(n=24)$, nitrofen non- $\mathrm{CDH}(n=37)$, $\mathrm{DM}$ treated $\mathrm{CDH}(n=30)$, sildenafil treated $\mathrm{CDH}(n=71)$, and DM+sildenafil treated $\mathrm{CDH}(n=32)$ fetuses were compared. ${ }^{*} P<0.05$ vs. nontreated $\mathrm{CDH}$ animals. $\mathrm{CDH}$, congenital diaphragmatic hernia; DM, dexamethasone.

a

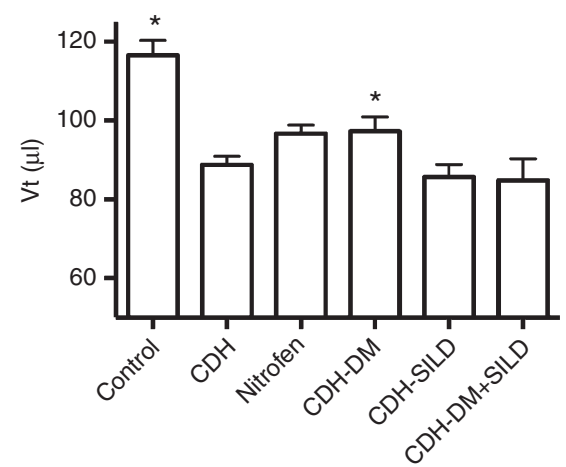

d

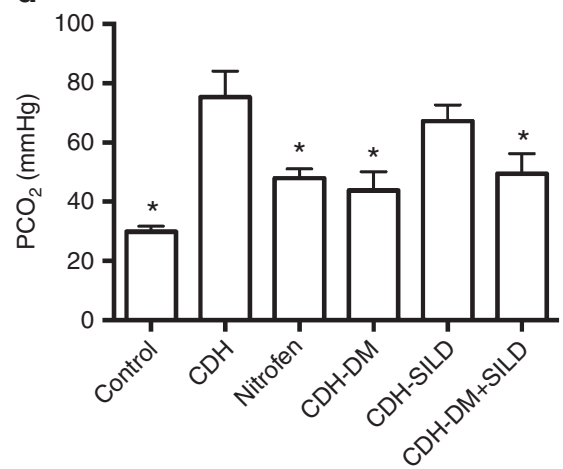

b

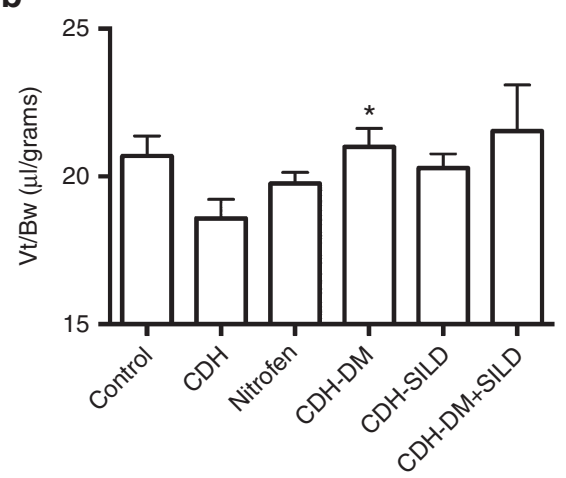

e

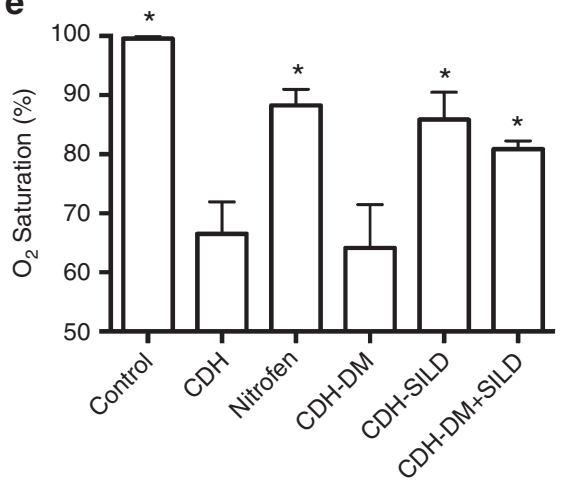

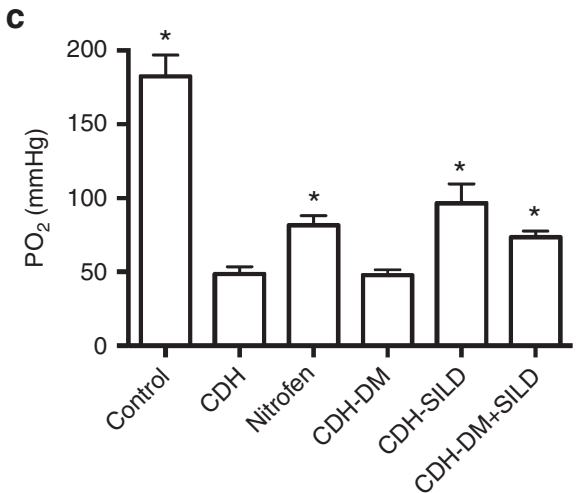

f

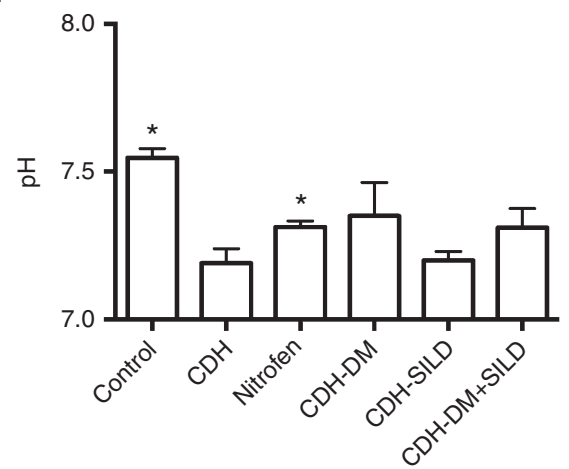

Figure 2. Tidal volumes $(\mathrm{Vt})$, oxygenation, and ventilation in $\mathrm{CDH}$ pups following prenatal $\mathrm{DM}$ and/or sildenafil treatment. $\mathrm{Vt}(\mathbf{a})$ and $\mathrm{Vt}$ per body weight (b) were measured following 30 min of ventilation in control $(n=22)$, nontreated $\mathrm{CDH}(n=15)$, nitrofen nonCDH $(n=30)$ and $\mathrm{CDH}$ pups treated with DM $(n=9)$, sildenafil $(n=7)$, or DM+sildenafil $(n=7)$. A mixed arteriovenous blood gas was obtained and the $\mathrm{PO}_{2}(\mathbf{c}), \mathrm{PCO}_{2}(\mathbf{d})$, oxygen saturation (e), and $\mathrm{pH}(\mathbf{f})$ were assessed in control $(n=9)$, nontreated $\mathrm{CDH}(n=10)$, nitrofen non-CDH $(n=20)$ and CDH pups treated with DM $(n=6)$, sildenafil $(n=7)$, or $\mathrm{DM}+$ sildenafil $(n=6) .{ }^{*} P<0.05$ vs. nontreated $\mathrm{CDH}$ animals. $\mathrm{CDH}$, congenital diaphragmatic hernia; $\mathrm{DM}$, dexamethasone. 
$\mathrm{CDH}$ pups was assessed. Controls and $\mathrm{CDH}$ pups treated with DM demonstrated increased Vt compared with nontreated $\mathrm{CDH}$ pups suggesting improved pulmonary compliance (Figure 2a). Prenatal treatment of $\mathrm{CDH}$ pups with sildenafil or DM+sildenafil did not have a significant effect on Vt. When adjusted for body weight, Vt of DM-treated CDH pups remained significantly increased and other treatments demonstrated an increased trend in Vt compared with nontreated $\mathrm{CDH}$ pups (Figure 2b).

A mixed arteriovenous blood gas and peripheral oxygen saturation were assessed at the completion of ventilation (Figure 2c-f). CDH pups demonstrated significantly worse oxygenation and ventilation compared with control and nitrofen exposed non-CDH pups (Figure $2 \mathrm{c}-\mathrm{e}$ ). Prenatal sildenafil treatment of $\mathrm{CDH}$ pups resulted in improved oxygenation compared with nontreated $\mathrm{CDH}$ pups while treatment with DM alone did not (Figure 2c-e). In contrast to oxygenation trends, prenatal DM improved ventilation (lower $\mathrm{CO}_{2}$ values) while prenatal sildenafil did not (Figure 2d). Treatment with $\mathrm{DM}+$ sildenafil capitalized on the beneficial effects of each treatment with $\mathrm{CDH}$ pups demonstrating increased oxygen saturations and $\mathrm{PO}_{2}$ values, and decreased $\mathrm{PCO}_{2}$ values compared with nontreated $\mathrm{CDH}$ controls (Figure 2c-e).

Alterations in oxygenation and ventilation translated into trends in acid-base statuses (Figure 2f). Nontreated $\mathrm{CDH}$ pups demonstrated a respiratory acidosis $(\mathrm{pH}: 7.19 \pm 0.05)$. In contrast, controls had a respiratory alkalosis ( $\mathrm{pH}: 7.55 \pm 0.03)$. $\mathrm{CDH}$ pups treated with sildenafil demonstrated an acidosis ( $\mathrm{pH}: 7.2 \pm 0.03$ ) related to poor ventilation while those treated with $\mathrm{DM}$ or $\mathrm{DM}+$ sildenafil had an improved acid-base status ( $\mathrm{pH}$ : $7.35 \pm 0.11$ and $7.31 \pm 0.06$ respectively).

Similar trends in $\mathrm{PO}_{2}, \mathrm{PCO}_{2}$, oxygen saturation and $\mathrm{pH}$ were observed in nitrofen-exposed non-CDH animals in the different prenatal treatment groups (data not shown).

\section{Imaging}

High-frequency fetal ultrasound was performed at the end of gestation to determine the effect of DM and/or sildenafil on the pulsatility index (PI), PA acceleration time (PAAT), and resistance index (RI) in the main PA. The PI, a measure of small vessel resistance to pulsatile flow, reflects pulmonary vascular impedance (19). Pulmonary vascular resistance and $\mathrm{PI}$ are increased in pulmonary hypoplasia and, in human $\mathrm{CDH}$ fetuses, an increased PI correlates with more severe pulmonary hypoplasia $(20,21)$. Correction of pulmonary hypoplasia results in a decrease in the PI in large animal CDH models (22). We compared the PI of nontreated $\mathrm{CDH}$ fetuses to controls and fetuses undergoing prenatal treatment (Figure 3a). The PI of controls was reduced compared with nontreated $\mathrm{CDH}$ fetuses. Treatment with sildenafil or DM+sildenafil reduced the PI to values similar to controls. Treatment with DM alone resulted in no significant change in the PI. Additionally, RI was increased in $\mathrm{CDH}$ fetuses compared with controls. Prenatal treatment with $\mathrm{DM}+$ sildenafil reduced the RI while individual treatments did not have a significant effect (Figure 3b).

A shortening of the PAAT, or rapid acceleration to peak flow velocity, has been reported in patients with elevated PA pressure and tricuspid regurgitation (23). Additionally, a decreased PAAT has been documented in $\mathrm{CDH}$ fetuses with pulmonary hypoplasia and patients who had undergone $\mathrm{CDH}$ repair $(20,24,25)$. In this study, the PAAT was decreased in $\mathrm{CDH}$ fetuses compared with controls. None of the prenatal therapies significantly increased the PAAT (Figure 3c).

Similar trends in PI, RI, and PAAT were observed in nitrofen-exposed non-CDH fetuses in the different prenatal treatment groups (data not shown).

\section{Histology}

Lung morphometry including pulmonary epithelial surface density (Sv), alveolar volume density (Vva), interalveolar septal thickness and radial alveolar count (RAC) was assessed. Sv, Vva, and RAC were decreased while interalveolar septal thickness was increased in nontreated $\mathrm{CDH}$ pups compared with controls (Figure 4a-d). None of the prenatal treatments had a significant effect on Sv or RAC in CDH pups (Figure 4a,d). In contrast, prenatal treatment of $\mathrm{CDH}$ pups with $\mathrm{DM}$ or $\mathrm{DM}+$ sildenafil increased Vva and decreased interalveloar septal thickness compared with nontreated CDH pups (Figure 4b,c and Figure 5).
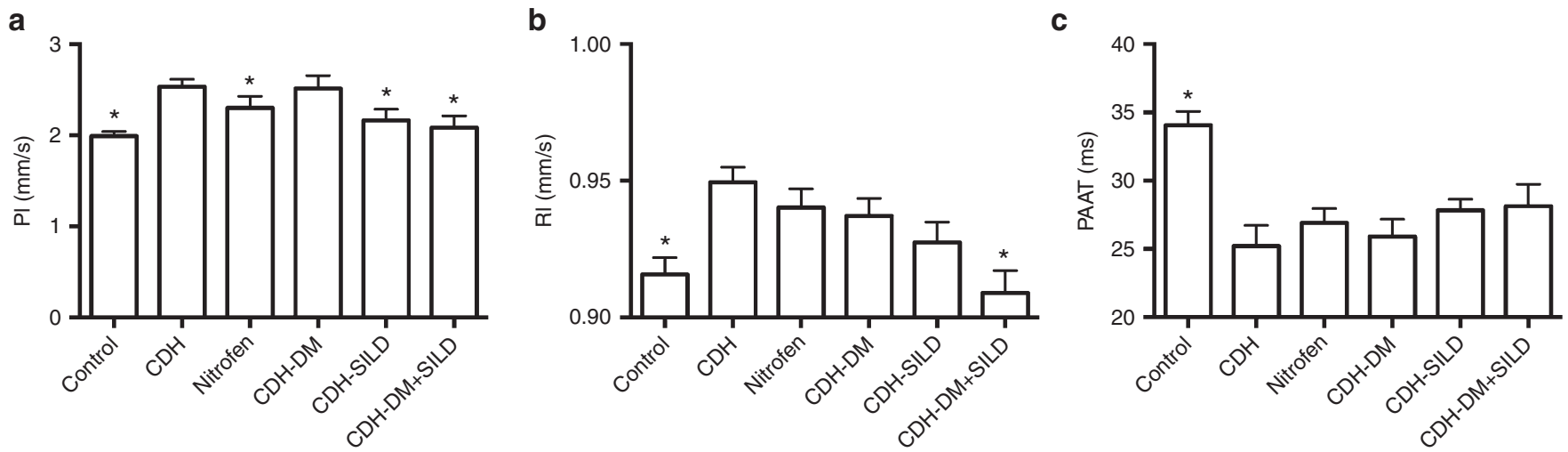

Figure 3. Doppler parameters in CDH pups following prenatal DM and/or sildenafil treatment. High frequency ultrasound imaging was performed at E21.5 following maternal laparotomy. The PI (a), RI (b), and PAAT (c) were measured in the PA in control $(n=45)$, nontreated CDH $(n=17)$, nitrofen non- $\mathrm{CDH}(n=23)$ and $\mathrm{CDH}$ fetuses treated with DM $(n=15)$, sildenafil $(n=31)$, or DM+sildenafil $(n=26) .{ }^{*} P<0.05$ vs. nontreated CDH animals. $\mathrm{CDH}$, congenital diaphragmatic hernia; DM, dexamethasone; PI, pulsatility index; RI. resistance index; PAAT, PA acceleration time; PA, pulmonary artery. 


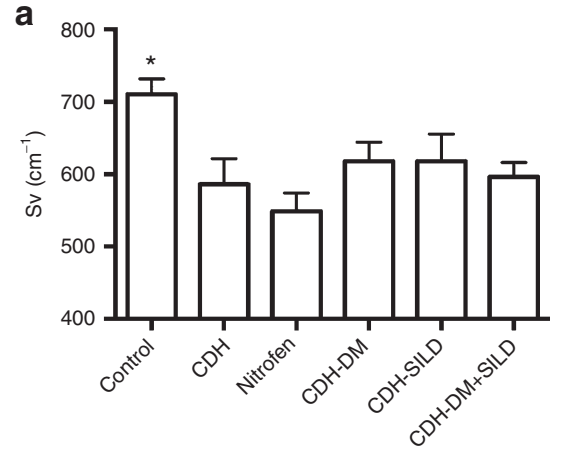

d

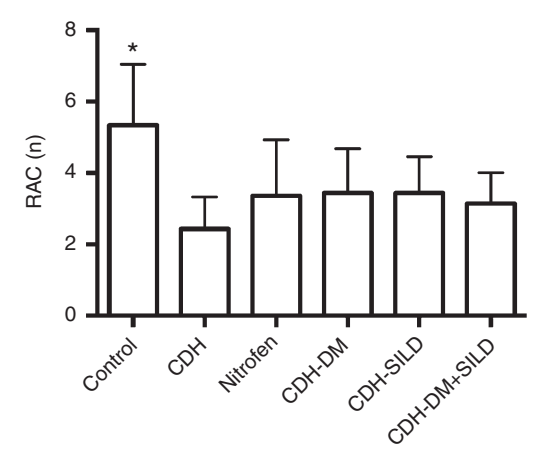

b

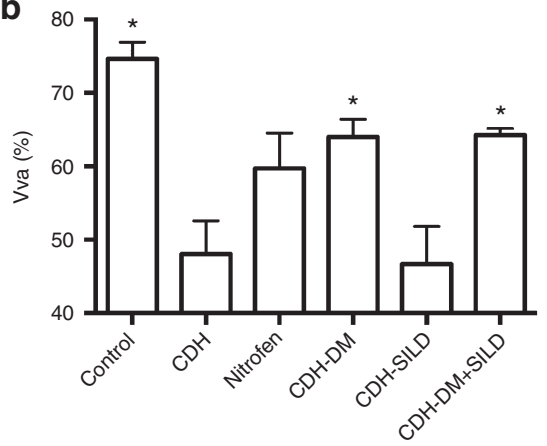

C

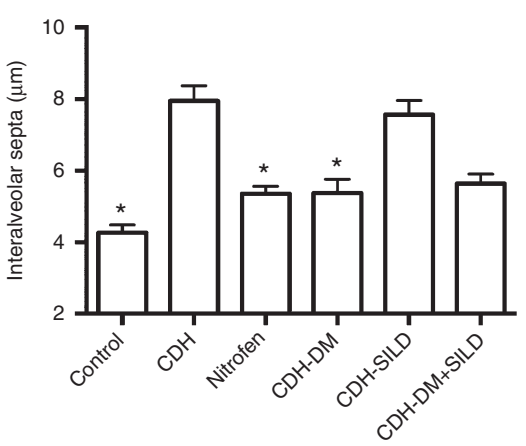

e

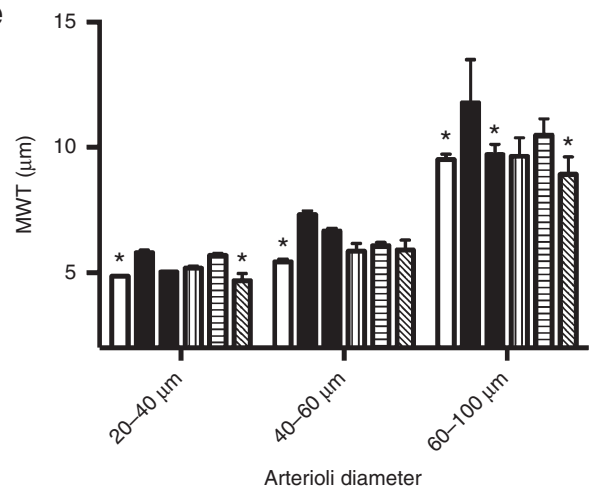

Figure 4. Lung morphometry and pulmonary arteriole MWT in CDH pups following prenatal DM and/or sildenafil treatment. Lungs were assessed for pulmonary epithelial surface density (Sv) (a), alveoli volume density (Vva) (b), interalveolar septal thickness (c), radial alveolar count (RAC) (d) and pulmonary arteriole MWT (e). For each parameter, a minimum of 5 slides per group were assessed in a blinded fashion. Analysis of the MWT (e) was divided into three groups based on the external diameter of the pulmonary arterioles and compared between controls (white columns), nontreated CDH (black columns), nitrofen non-CDH (gray columns) and CDH pups treated with DM (vertical-hatched columns), sildenafil (horizontal-hatched columns), or DM+sildenafil (diagonal-hatched columns). ${ }^{*} \mathrm{P}<0.05$ vs nontreated CDH animals. CDH, congenital diaphragmatic hernia; DM, dexamethasone; MWT, medial wall thickness.

The pulmonary arterioles were divided into three groups based on external diameter and medial wall thickness (MWT) was analyzed (Figure 4e and Figure 6). Nontreated $\mathrm{CDH}$ pups had significantly higher MWT compared with controls in all groups. Prenatal treatment with DM+sildenafil significantly reduced MWT in the 20-40 and 60-100 $\mu \mathrm{m}$ groups, and also demonstrated a trend toward decreased MWT in the 40-60 $\mu \mathrm{m}$ group. A nonsignificant trend toward decreased MWT in all groups following treatment with DM or sildenafil alone was noted.

\section{DISCUSSION}

A main contributor to the morbidity and mortality of $\mathrm{CDH}$ is pulmonary arterial hypermuscularization and hypertension associated with pulmonary hypoplasia acquired during fetal development $(2,3,26)$. Prenatal therapies that address these derangements offer the potential to improve outcomes. Although recent results from endoscopic TO are encouraging (survival $~ 50 \%$ in severe $\mathrm{CDH}$ ), the procedure has risks including preterm delivery, chorioamnionitis, and tracheal deformity (10). Maternally administered medical therapies offer hope of a less invasive strategy associated with decreased risks and may specifically target $\mathrm{PH}$ and hypoplasia. In our study, we demonstrate that maternal administration of DM and/or sildenafil in the rat $\mathrm{CDH}$ model results in improved pulmonary morphology associated with evidence of decreased $\mathrm{PH}$ on ultrasound and improved respiratory function after birth. Specifically, DM and DM+sildenafil reduced interalveolar septal thickness and increased Vva in $\mathrm{CDH}$ pups while $\mathrm{DM}+$ sildenafil also reduced MWT. The PA PI, a measure of pulmonary vascular impedance $(20,21)$, was significantly reduced in $\mathrm{CDH}$ pups exposed to sildenafil or DM+sildenafil while the RI was decreased in recipients of DM+sildenafil. These findings translated into improved postnatal oxygenation and ventilation following prenatal sildenafil and DM respectively. Treatment with DM+sildenafil harnessed the beneficial effects of individual treatments as indicated by improvements in both oxygenation and ventilation.

Prenatal administration of steroids in $\mathrm{CDH}$ animal models has been previously explored. In the surgically created sheep $\mathrm{CDH}$ model, prenatal glucocorticoids accelerated lung maturation and, when combined with TO, improved lung morphology and respiratory function after birth (27). In the rat CDH model, prenatal DM accelerated lung maturation, improved lung morphology, decreased medial wall hypertrophy, and improved lung compliance on postmortem insufflation studies $(15,28,29)$. The current study confirms these morphologic findings and extends the analysis, demonstrating that prenatal DM, independent of TO, is associated with improved respiratory function. Our results suggest that improved function results from increased 
a

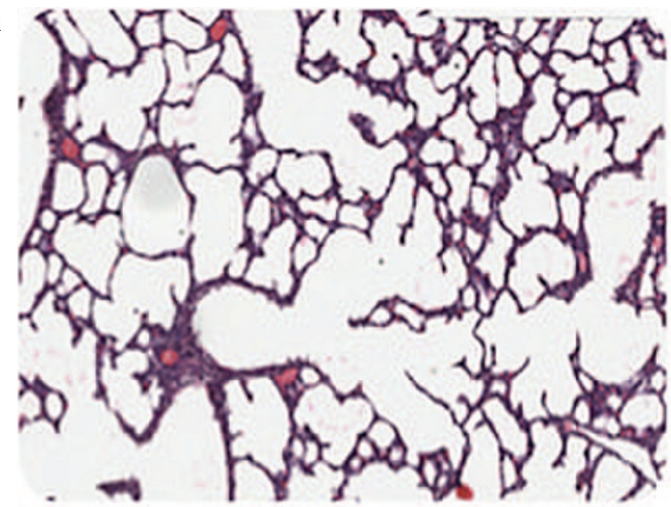

C

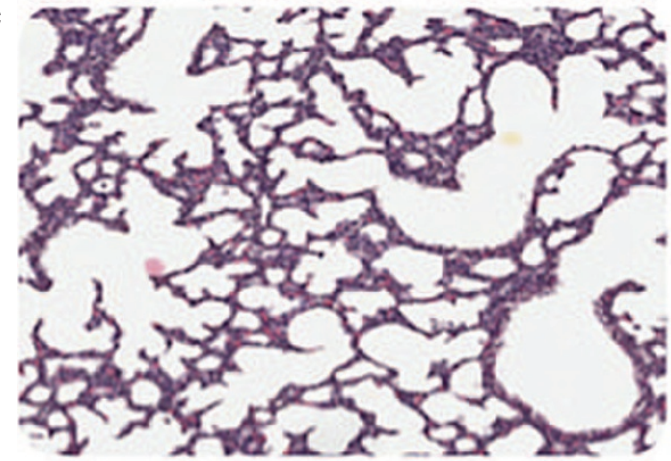

e

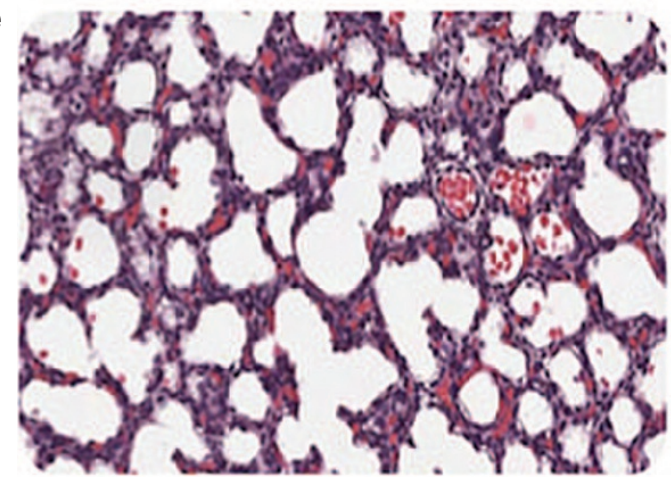

b

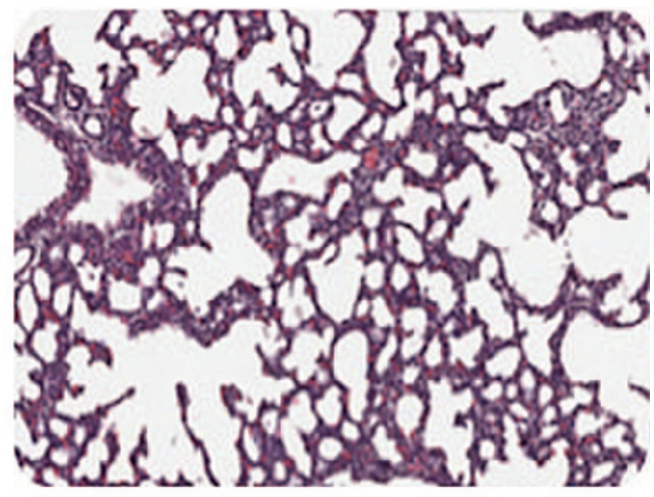

d

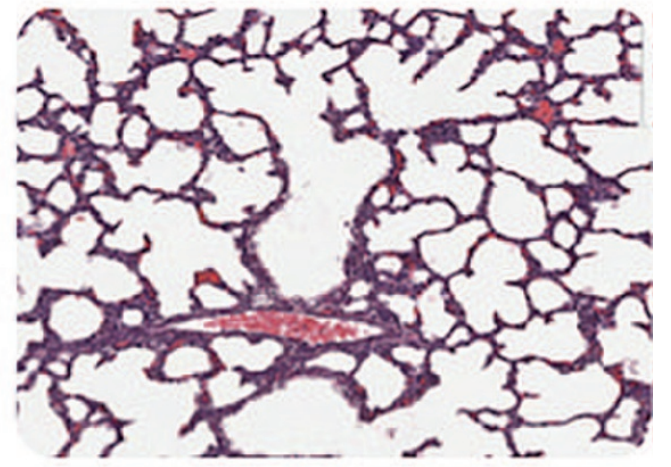

f

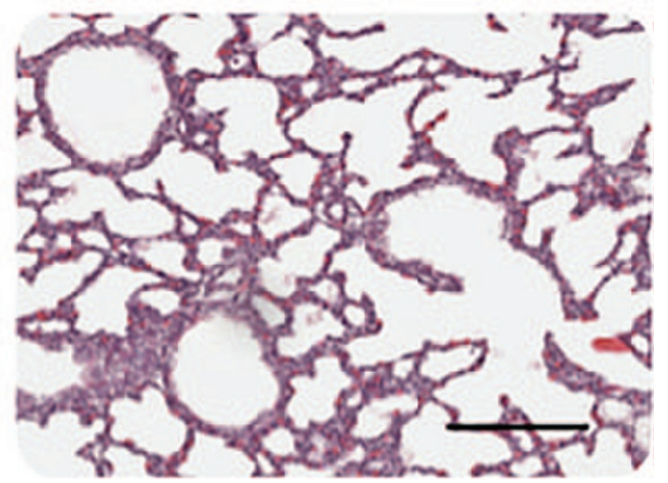

Figure 5. Lung morphometry. Representative pulmonary sections from controls (a), nontreated $\mathrm{CDH}$ (b), nitrofen non- $\mathrm{CDH}$ (c) and $\mathrm{CDH}$ pups treated with DM (d), sildenafil (e), or DM+sildenafil (f). Hematoxylin and eosin (H\&E); Magnification $\times 20$. Scale bar $=50 \mu m$. CDH, congenital diaphragmatic hernia; DM, dexamethasone.

pulmonary compliance as evidence by improved Vt and ventilation. Previous studies evaluated the effect of prenatal DM on biochemical pathways instrumental to pulmonary development and function $(13,14)$. These studies demonstrate increased surfactant production by type II cells in response to glucocorticoids $(13,30)$, which could contribute to improved pulmonary compliance and ventilation following prenatal DM in our study. Additional studies found a transient increase in endothelial nitric oxide synthase and decreased angiotensin converting enzyme expression associated with prenatal DM $(14,15)$. These alternations would be expected to decrease $\mathrm{PH}$, however, we did not find ultrasound evidence suggesting decreased pulmonary resistance and improved pulmonary blood flow following DM alone. This may reflect a limitation of the short amount of time that pulmonary blood flow can be assessed in our study.
The management of $\mathrm{PH}$ with sildenafil is based on its ability to increase cyclic GMP and augment pulmonary vasodilatation. It is used to treat persistent $\mathrm{PH}$ of the newborn where, in appropriate cases, it improves oxygenation and reduces mortality (31). Recently, it has become part of the armamentarium for postnatal management of $\mathrm{PH}$ in $\mathrm{CDH}$ (32). In the rat $\mathrm{CDH}$ model, antenatal sildenafil improved lung morphology, increased pulmonary vessel density, and reduced right ventricular hypertrophy (17). Its effect on pulmonary vascular development in the rat model is varied $(33,34)$. It was noted to attenuate vascular remodeling and decrease pulmonary arterial MWT in the studies by Lemus-Varela et al. (33) and Luong et al. (17). In contrast, Kattan et al. (34) demonstrated no significant change in MWT but noted an increase in the number of pulmonary arterioles. This study also found an 


\section{Articles | Burgoset al.}
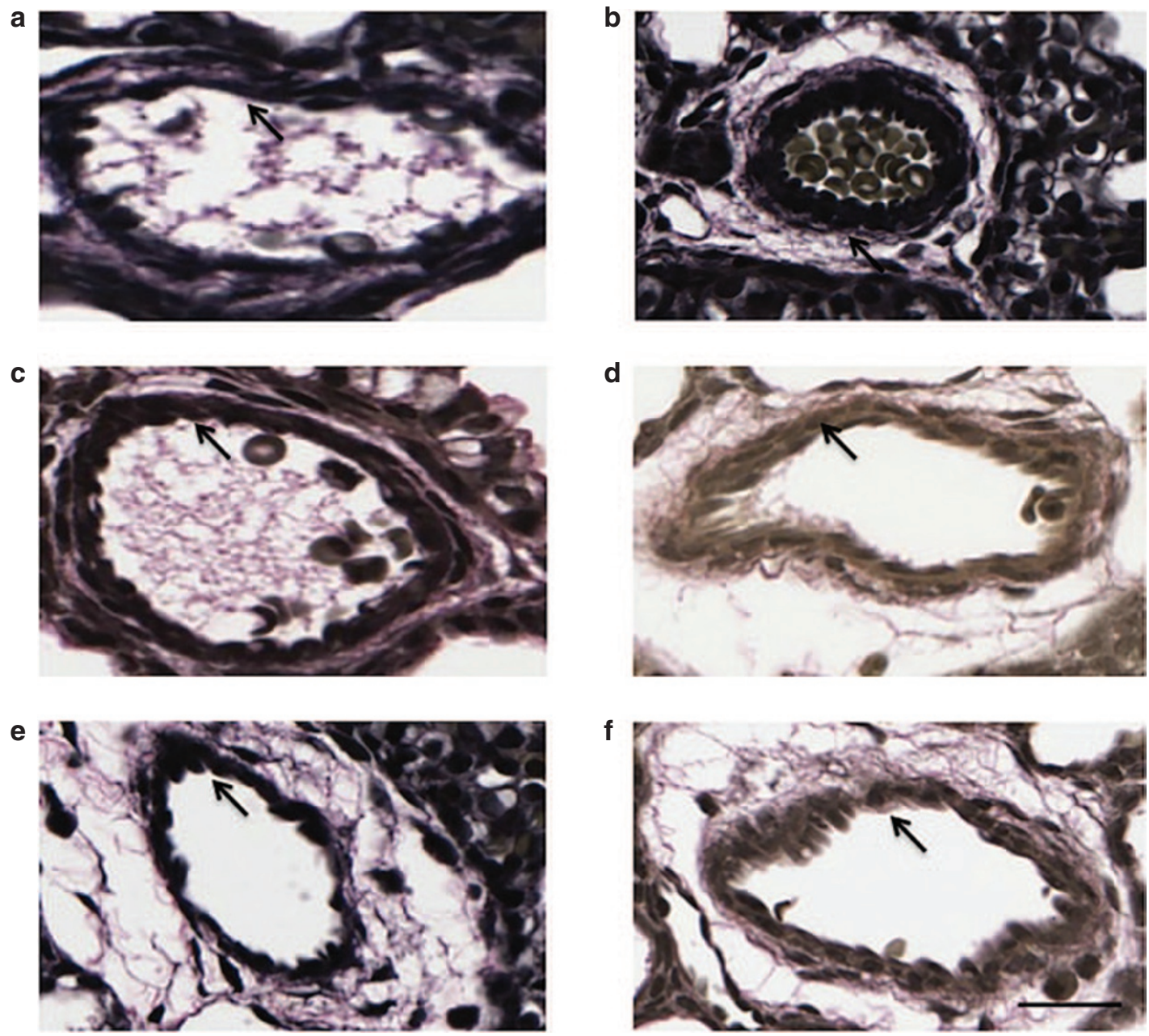

Figure 6. Pulmonary arteriole analysis. Representative section of the pulmonary arteriole of the same diameter from controls (a), nontreated CDH (b), nitrofen non-CDH (c) and CDH pups treated with DM (d), sildenafil (e), or DM+sildenafil (f). The MWT of the arteriole was thicker in nontreated $\mathrm{CDH}$ compared with controls. Different treatments had varied effects on the MWT depending on the arterioli diameter (see Figure 4, panel e). Elastin; Magnification $\times 40$. Arrows $(\rightarrow)$ indicate measured medial arteriole wall, Scale bar $=25 \mu \mathrm{m}$. CDH, congenital diaphragmatic hernia; DM, dexamethasone; MWT, medial wall thickness.

increase in MWT following antenatal DM in contrast to previous studies that suggested DM decreased MWT (15). In our study, we found a significant decrease in MWT following DM+sildenafil and a trend toward decreased MWT following individual treatments (DM $>$ sildenafil effect). The etiology of this effect is unclear but could be related to inhibition of smooth muscle proliferation (15). Furthermore, we expand on these histologic findings and demonstrate a reduction in PA vascular impedance following antenatal sildenafil suggestive of decreased $\mathrm{PH}$ and improved oxygenation, suggestive of improved neonatal lung function. Mechanistically, previous studies demonstrated increased lung cyclic GMP production and decreased active PDE5 expression following prenatal and neonatal sildenafil treatment in rat $\mathrm{CDH}$ and bronchopulmonary dysplasia (BPD) models $(17,18)$. Increased alveolarization was also noted with sildenafil under hyperoxia conditions in the bronchopulmonary dysplasia model (18). We did not appreciate a significant increase in alveolarization in our study. The previous studies also demonstrated increased pulmonary production of vascular endothelial growth factor, endothelial nitric oxide synthase, hypoxia-inducible factor $-1 / 2 \alpha$ and increased PA relaxation following $\mathrm{NO}$ exposure in rats treated with sildenafil $(17,18)$. These biochemical changes may, in part, explain the increased oxygenation and pulmonary blood flow, and decreased pulmonary resistance following antenatal sildenafil in our study.

Although encouraging, the results, this study must be approached with caution. Limitations include the use of a mixed arteriovenous blood gas instead of a pure arterial blood gas to assess functional improvement following prenatal pharmacologic treatments. This was due to technical limitations of obtaining an adequate volume of nonmixed arterial blood. Additionally, we failed to demonstrate a significant change in RAC, and the effect of prenatal DM and/or sildenafil on lung architecture needs to be interpreted with caution, in light of the representative histology in which a differential effect is difficult to appreciate. Finally, the most concerning finding and limitation is a potential detrimental effect of prenatal DM 
and/or sildenafil on lung and fetal growth. We demonstrate a decrease in the Lw:Bw ratio suggesting a detrimental effect on lung growth following all prenatal treatments. A decrease in $\mathrm{Lw}$ and Lw:Bw ratio was previously demonstrated in normal rats treated with antenatal DM (35). In this study, the most significant decrease occurred immediately after administering DM and values approached controls by $15-20 \mathrm{~d}$ of life. Survival in our study was limited to the immediate perinatal period, and thus the effect of DM on lung growth at later time points could not be assessed. One of the novel observations in our study was the growth restrictive effect, represented by decreased Lw, Bw, and Lw:Bw ratio of sildenafil. Previous studies in the rat model of intrauterine growth restriction have suggested a negative effect of sildenafil on birth weight but did not assess its effect on lung growth (36). In our study, sildenafil was administered at E11.5 using a dose and duration previously shown to have the desired morphologic and biochemical effects on fetal lung (17). This corresponds to the pseudoglandular stage of lung development during which airway branching and morphogenesis occur. This is also a time of significant fetal growth and thus the potential to effect growth exists. Additionally, E11.5 corresponds to $\sim 10-12 \mathrm{wk}$ gestation in humans. Clinically, sildenafil would likely be administered later in gestation. Further experiments evaluating the optimal dose, duration, and clinically relevant timing of sildenafil which maximize beneficial pulmonary effects while minimizing growth restrictive effects are required. Finally, previous studies in humans with $\mathrm{CDH}$ demonstrated different effects of prenatal steroids on postnatal outcomes. An initial report of three cases documented improved outcomes following prolonged steroid administration beginning at 24-26 wk gestation in $\mathrm{CDH}$ fetuses categorized as "poor prognosis" (11). More recently, a prospective randomized multicenter trial in which three courses of steroids were given at 34-36 wk demonstrated no improvement in outcomes (12). In our study, DM was administered at a gestational age of lung development approximating a 24-26wk human fetus which may explain our results in the context of the clinical studies. Furthermore, both clinical studies are limited by sample size and failure to stratify patients according to predictors of disease severity. These studies demonstrate the importance of using prenatal predictors of disease severity for patient selection prior to prenatal interventions and in subsequent interpretation of results (7-9). The disparate results between the multicenter clinical trial and our study combined with the potential detrimental effect prenatal DM and sildenafil on fetal lung growth highlight the importance of large animal preclinical models and caution in translating findings from the rat $\mathrm{CDH}$ model to clinical application.

Prenatal therapies that improve $\mathrm{PH}$ and respiratory function at birth in $\mathrm{CDH}$ patients offer the potential to significantly improve outcomes in this challenging population. Previous studies have suggested the potential of prenatal pharmacologic interventions based on improved lung morphology and alterations in biochemical pathways. The novelty of the current study is twofold: (i) It correlates the beneficial morphologic effects of prenatal DM or sildenafil treatment with an improvement in pulmonary compliance and pulmonary vascular resistance which is subsequently associated with improved neonatal gas exchange and (ii) it highlights the potential therapeutic effects of a combined treatment approach with more than one pharmacologic agent. These findings support the need for more rigorous studies in preclinical large animal models and offer hope for future prenatal pharmacologic therapies in the management of $\mathrm{CDH}$.

\section{METHODS}

\section{Animal Model}

Time-dated pregnant Sprague-Dawley rats were gavage fed $100 \mathrm{mg}$ of nitrofen (Sigma-Aldrich, St. Louis, MO) dissolved in $1 \mathrm{ml}$ olive oil at embryonic (E) day 9.5 to create $\mathrm{CDH}$. Dams were randomized into three treatment groups: (i) CDH+DM (Dexamethasone Sodium Phosphate; Pfizer, Wayne, PA; $0.25 \mathrm{mg} / \mathrm{kg}$, i.p. on E18.5 and E19.5), (ii) $\mathrm{CDH}+$ sildenafil (Sildenafil citrate; Pfizer; $100 \mathrm{mg} / \mathrm{kg}$ daily, subcutaneously from E11.5 to E20.5), and (iii) CDH+combination DM/ sildenafil. Controls received olive oil only. A maternal laparotomy was performed under isoflurane anesthesia at E21.5 and the uterus was exposed for perinatal pup ventilation and imaging studies. Fetuses with right-sided and bilateral $\mathrm{CDH}$ were excluded. Experimental protocols were approved by the Institutional Animal Care and Use Committee at The Children's Hospital of Philadelphia and followed guidelines in the NIH's Guide for the Care and Use of Laboratory Animals.

\section{Ventilation Studies}

Ultrasound (Philips nr MZ 540-66,500; Philips, Baltimore, MD) confirmed a $\mathrm{CDH}$ at E21.5, after which a fetal tracheostomy was performed on placental support using a modified $24 \mathrm{G}$ endotracheal tube (Insyte Autogard 24GA, Becton Dickinson, Franklin Lakes, NJ) and cyanoacrylate glue (Vetbond, 3M Animal Care Products, St Paul, MN) to obtain an airtight seal. The umbilical cord was transected and pups were ventilated (Harvard 683). Ventilator settings were: $\mathrm{FiO}_{2} 0.6$, frequency $120 / \mathrm{min}$, I:E ratio $1: 2$, peak inspiratory pressure $20 \mathrm{~cm} \mathrm{H}_{2} \mathrm{O}$, positive end-expiratory pressure $1 \mathrm{~cm} \mathrm{H}_{2} \mathrm{O}$. Airway pressure was measured continuously (TruWave, Catalog\# PX284, Edwards Lifesciences, Irvine, CA) from the inspiratory limb of the circuit. Peak inspiratory pressure was maintained at $20 \mathrm{~cm} \mathrm{H}_{2} \mathrm{O}$ by adjusting ventilator stroke volume. After $30 \mathrm{~min}$ of ventilation, a low resistance syringe was attached to the circuit and the syringe volume measured after 12-15 ventilator cycles. The estimated stroke volume was calculated:

\section{Stroke volume $=$ syringe volume $(\mathrm{ml}) /$ No of ventilator cycles}

Vts were determined based on preliminary experiments performed at $0 \mathrm{mmHg}$ which indicated that the Vt was $38 \%$ lower than the measured stroke volumes. A mixed arteriovenous blood gas was assessed after 30 min of ventilation (I-Stat 1 Analyzer; Abbott, Princeton, NJ). In order to obtain an adequate volume of blood for analysis, the subclavian artery and vein were transected and arterial and venous blood combined.

\section{Imaging Studies}

A fetal chest transverse cross-sectional view was obtained at the level of the 4-chamber view of the heart using B-mode (Vevo 2,100 Imaging System with integrated MS-700 transducer; VisualSonics, Toronto, Canada). Color Doppler imaging identified the PA proximal to its bifurcation and blood velocity waveforms were recorded (19). Heart rate, ejection velocity, PAAT, PI, and RI were calculated $(19,37)$ :

$\mathrm{PI}=($ peak systolic velocity - end diastolic velocity $) /$ time averaged velocity

$\mathrm{RI}=($ peak systolic velocity - end diastolic velocity $) /$ peak systolic velocity

PAAT $=$ the interval between onset of systolic PA flow and peak flow velocity

Analyses represent the average of five consecutive cardiac cycles. 


\section{Histology}

Trachea and lungs were harvested en bloc, weighed and pressurefixed with $10 \%$ formalin to a distending pressure of $20 \mathrm{~cm} \mathrm{H}_{2} \mathrm{O}$ (38). Specimens were embedded in paraffin, sectioned at $4 \mu \mathrm{m}$ and stained with either hematoxylin and eosin or Elastin van Geison. Histological analyses were performed by two independent examiners blinded to study group. Measurements of linear intercept (Lm), Sv (Sv $=4 \times$ $\mathrm{Lm} / \mathrm{L} \times$ probe length $\mathrm{cm}-1)$, Vva, interalveolar septa width, MWT of pulmonary arterioles, and RAC were obtained $(27,39,40)$.

\section{Statistics}

Data are presented as mean \pm SEM. Statistical comparisons between groups were performed with the nonparametric Mann-Whitney test. Significance was defined as $P \leq 0.05$. Analyses were performed using PRISM 6 (Graphpad Software, La Jolla, CA).

\section{STATEMENT OF FINANCIAL SUPPORT}

The study received funding in part from the Hirsch fund at Karolinska Institute (CMB; Stockholm, Sweden) and the Crown Princess Lovisa's Memorial Fund (CMB; Stockholm, Sweden) and generous family gifts to The Children's Hospital of Philadelphia (Philadelphia, Pennsylvania).

Disclosure: The authors have nothing to disclose and declare no conflict of interest.

\section{REFERENCES}

1. Hedrick HL. Management of prenatally diagnosed congenital diaphragmatic hernia. Semin Pediatr Surg 2013;22:37-43.

2. Trachsel D, Selvadurai H, Bohn D, Langer JC, Coates AL. Long-term pulmonary morbidity in survivors of congenital diaphragmatic hernia. Pediatr Pulmonol 2005;39:433-9.

3. Vijfhuize S, Schaible T, Kraemer U, Cohen-Overbeek TE, Tibboel D, Reiss I. Management of pulmonary hypertension in neonates with congenital diaphragmatic hernia. Eur J Pediatr Surg 2012;22:374-83.

4. Sabharwal AJ, Davis CF, Howatson AG. Post-mortem findings in fetal and neonatal congenital diaphragmatic hernia. Eur J Pediatr Surg 2000;10:96-9.

5. van Dooren MF, Goemaere NN, de Klein A, Tibboel D, de Krijger RR. Postmortem findings and clinicopathological correlation in congenital diaphragmatic hernia. Pediatr Dev Pathol 2004;7:459-67.

6. de Lagausie P, de Buys-Roessingh A, Ferkdadji L, et al. Endothelin receptor expression in human lungs of newborns with congenital diaphragmatic hernia. J Pathol 2005;205:112-8.

7. Jani J, Keller RL, Benachi A, et al.; Antenatal-CDH-Registry Group. Prenatal prediction of survival in isolated left-sided diaphragmatic hernia. Ultrasound Obstet Gynecol 2006;27:18-22.

8. Ruano R, Aubry MC, Barthe B, Dumez Y, Zugaib M, Benachi A. Threedimensional sonographic measurement of contralateral lung volume in fetuses with isolated congenital diaphragmatic hernia. J Clin Ultrasound 2008;36:273-8.

9. Bebbington M, Victoria T, Danzer E, et al. Comparison of ultrasound and magnetic resonance imaging parameters in predicting survival in isolated left-sided congenital diaphragmatic hernia. Ultrasound Obstet Gynecol 2014;43:670-4.

10. Deprest J, Brady P, Nicolaides K, et al. Prenatal management of the fetus with isolated congenital diaphragmatic hernia in the era of the TOTAL trial. Semin Fetal Neonatal Med 2014;19:338-48.

11. Ford WD, Kirby CP, Wilkinson CS, Furness ME, Slater AJ. Antenatal betamethasone and favourable outcomes in fetuses with 'poor prognosis' diaphragmatic hernia. Pediatr Surg Int 2002;18:244-6.

12. Lally KP, Bagolan P, Hosie S, et al.; Congenital Diaphragmatic Hernia Study Group. Corticosteroids for fetuses with congenital diaphragmatic hernia: can we show benefit? J Pediatr Surg 2006;41:668-74; discussion $668-74$.

13. Guarino N, Oue T, Shima H, Puri P. Antenatal dexamethasone enhances surfactant protein synthesis in the hypoplastic lung of nitrofen-induced diaphragmatic hernia in rats. J Pediatr Surg 2000;35:1468-73.
14. Okoye BO, Losty PD, Fisher MJ, Hughes AT, Lloyd DA. Antenatal glucocorticoid therapy suppresses angiotensin-converting enzyme activity in rats with nitrofen-induced congenital diaphragmatic hernia. J Pediatr Surg 1998;33:286-91.

15. Okoye BO, Losty PD, Lloyd DA, Gosney JR. Effect of prenatal glucocorticoids on pulmonary vascular muscularisation in nitrofen-induced congenital diaphragmatic hernia. J Pediatr Surg 1998;33:76-80.

16. Bialkowski A, Moenkemeyer F, Patel N. Intravenous sildenafil in the management of pulmonary hypertension associated with congenital diaphragmatic hernia. Eur J Pediatr Surg 2015;25:171-6.

17. Luong C, Rey-Perra J, Vadivel A, et al. Antenatal sildenafil treatment attenuates pulmonary hypertension in experimental congenital diaphragmatic hernia. Circulation 2011;123:2120-31.

18. Park HS, Park JW, Kim HJ, et al. Sildenafil alleviates bronchopulmonary dysplasia in neonatal rats by activating the hypoxia-inducible factor signaling pathway. Am J Respir Cell Mol Biol 2013;48:105-13.

19. Laudy JA. Doppler ultrasonography of the human fetal pulmonary circulation. Eur J Obstet Gynecol Reprod Biol 2001;99:3-5.

20. Chaoui R, Kalache K, Tennstedt C, Lenz F, Vogel M. Pulmonary arterial Doppler velocimetry in fetuses with lung hypoplasia. Eur J Obstet Gynecol Reprod Biol 1999;84:179-85.

21. Laudy JA, Tibboel D, Robben SG, de Krijger RR, de Ridder MA, Wladimiroff JW. Prenatal prediction of pulmonary hypoplasia: clinical, biometric, and Doppler velocity correlates. Pediatrics 2002;109:250-8.

22. Sylvester KG, Rasanen J, Kitano Y, Flake AW, Crombleholme TM, Adzick NS. Tracheal occlusion reverses the high impedance to flow in the fetal pulmonary circulation and normalizes its physiological response to oxygen at full term. J Pediatr Surg 1998;33:1071-4; discussion 1074-5.

23. Kitabatake A, Inoue M, Asao M, et al. Noninvasive evaluation of pulmonary hypertension by a pulsed Doppler technique. Circulation 1983;68: 302-9.

24. Abolmaali N, Koch A, Götzelt K, Hahn G, Fitze G, Vogelberg C. Lung volumes, ventricular function and pulmonary arterial flow in children operated on for left-sided congenital diaphragmatic hernia: long-term results. Eur Radiol 2010;20:1580-9.

25. Dabestani A, Mahan G, Gardin JM, et al. Evaluation of pulmonary artery pressure and resistance by pulsed Doppler echocardiography. Am J Cardiol 1987;59:662-8.

26. van den Hout L, Schaible T, Cohen-Overbeek TE, et al. Actual outcome in infants with congenital diaphragmatic hernia: the role of a standardized postnatal treatment protocol. Fetal Diagn Ther 2011;29:55-63.

27. Davey MG, Danzer E, Schwarz U, et al. Prenatal glucocorticoids improve lung morphology and partially restores surfactant mRNA expression in lambs with diaphragmatic hernia undergoing fetal tracheal occlusion. Pediatr Pulmonol 2006;41:1188-96.

28. Losty PD, Suen HC, Manganaro TF, Donahoe PK, Schnitzer JJ. Prenatal hormonal therapy improves pulmonary compliance in the nitrofeninduced CDH rat model. J Pediatr Surg 1995;30:420-6.

29. Schnitzer JJ, Hedrick HL, Pacheco BA, et al. Prenatal glucocorticoid therapy reverses pulmonary immaturity in congenital diaphragmatic hernia in fetal sheep. Ann Surg 1996;224:430-7; discussion 437-9.

30. Provost PR, Boucher E, Tremblay Y. Glucocorticoid metabolism in the developing lung: adrenal-like synthesis pathway. J Steroid Biochem Mol Biol 2013;138:72-80

31. Shah PS, Ohlsson A. Sildenafil for pulmonary hypertension in neonates. Cochrane Database Syst Rev 2011:CD005494.

32. Hunter L, Richens T, Davis C, Walker G, Simpson JH. Sildenafil use in congenital diaphragmatic hernia. Arch Dis Child Fetal Neonatal Ed 2009;94:F467.

33. Lemus-Varela Mde L, Soliz A, Gómez-Meda BC, et al. Antenatal use of bosentan and/or sildenafil attenuates pulmonary features in rats with congenital diaphragmatic hernia. World J Pediatr 2014;10:354-9.

34. Kattan J, Céspedes C, González A, Vio CP. Sildenafil stimulates and dexamethasone inhibits pulmonary vascular development in congenital diaphragmatic hernia rat lungs. Neonatology 2014;106:74-80. 
35. Schellenberg JC, Liggins GC, Stewart AW. Growth, elastin concentration, and collagen concentration of perinatal rat lung: effects of dexamethasone. Pediatr Res 1987;21:603-7.

36. Nassar AH, Masrouha KZ, Itani H, Nader KA, Usta IM. Effects of sildenafil in $\mathrm{N} \omega$-nitro-L-arginine methyl ester-induced intrauterine growth restriction in a rat model. Am J Perinatol 2012;29:429-34.

37. Yared K, Noseworthy P, Weyman AE, McCabe E, Picard MH, Baggish AL. Pulmonary artery acceleration time provides an accurate estimate of systolic pulmonary arterial pressure during transthoracic echocardiography. J Am Soc Echocardiogr 2011;24:687-92.
38. Davey MG, Hedrick HL, Bouchard S, et al. Temporary tracheal occlusion in fetal sheep with lung hypoplasia does not improve postnatal lung function. J Appl Physiol (1985) 2003;94:1054-62.

39. Emery JL, Mithal A. The number of alveoli in the terminal respiratory unit of man during late intrauterine life and childhood. Arch Dis Child 1960;35:544-7.

40. Hsia CC, Hyde DM, Ochs M, Weibel ER; ATS/ERS Joint Task Force on Quantitative Assessment of Lung Structure. An official research policy statement of the American Thoracic Society/European Respiratory Society: standards for quantitative assessment of lung structure. Am J Respir Crit Care Med 2010;181:394-418. 